\title{
PENGARUH PENDIDIKAN KESEHATAN PENCAPAIAN IDENTITAS PERAN IBU PADA WANITA YANG MENIKAH DINI
}

\section{EFFECTIVENESS OF MATERNAL ROLE ATTAINMENT HEALTH EDUCATION ON EARLY MARRIED WOMEN}

\author{
Dora Samaria $^{1}$, Elsi Dwi Hapsari ${ }^{2}$, Nuring Pangastuti ${ }^{3}$ \\ ${ }^{1}$ Faculty of Nursing Universitas Pelita Harapan \\ 2Program Studi Magister Keperawatan Universitas Gadjah Mada \\ ${ }^{3}$ Fakultas Kedokteran Universitas Gadjah Mada \\ Email: dora.samaria@uph.edu
}

\begin{abstract}
ABSTRAK
Latar Belakang: Wanita menikah dini berisiko tidak mencapai identitas peran ibu secara optimal. Pendidikan kesehatan dapat meningkatkan kepercayaan diri, kepuasan peran ibu, dan ikatan tali kasih ibu-bayi yang merupakan indikator pencapain identitas peran ibu. Pendidikan kesehatan belum pernah diberikan kepada wanita menikah dini di Bantul, Yogyakarta. Tujuan: Mengidentifikasi efektivitas Pendidikan Kesehatan Pencapaian Identitas Peran lbu dalam meningkatkan kepercayaan diri dan kepuasan peran ibu serta ikatan tali kasih ibu-bayi pada wanita menikah dini. Metode: Penelitian ini merupakan quasi-eksperimen dengan pretest and posttest design. Kriteria inklusi meliputi wanita berusia 24 tahun dan kurang, menikah usia 18 tahun dan kurang, dan hanya memiliki bayi usia 0-12 bulan. Kelompok Pendidikan Kesehatan Pencapaian Identitas Peran lbu (Penkes PIPI) $(\mathrm{n}=30)$ diberikan pendidikan kesehatan individu dengan booklet, demonstrasi dan latihan perawatan bayi, serta konseling telepon setelah intervensi. Kelompok ceramah $(\mathrm{n}=30)$ hanya diberikan edukasi individu. Hasil: Kelompok Penkes PIPI memiliki skor kepercayaan diri dan kepuasan peran ibu serta ikatan tali kasih ibu-bayi lebih tinggi daripada kelompok ceramah ( $p$ value $<0,05$ ). Diskusi: Penelitian ini menunjukkan bahwa Penkes PIPI efektif meningkatkan pencapaian identitas peran ibu pada wanita menikah dini. Disarankan penggunaan desain penelitian acak untuk penelitian selanjutnya.
\end{abstract}

Kata kunci: kepuasan peran ibu, pendidikan kesehatan identitas peran ibu, dan pernikahan dini.

\begin{abstract}
Background: Early married women may not reach maternal role identity optimally. Health education improves maternal confidence, maternal role satisfaction and mother-baby attachment which are indicators of maternal role attainment. It had never been given to early married women in Bantul, Yogyakarta. Objective: To identify effectiveness of Maternal Role Attainment Health Education in improving selfconfidence and maternal role satisfaction as well as mother-baby attachment in early married women. Methods: This study applied a quasi-experiment with pretest and posttest design. Inclusion criteria included women aged 24 years old and below, who got married at 18 years old and below, and having baby only aged 0-12 months. Penkes PIPI group $(n=30)$ was given individual health education with booklet, demonstration and baby care training, and telephone counseling after intervention. Lecture group $(n=30)$ was given only individual health education. Results: Intervention group scored higher on self-confidence and maternal role satisfaction, and motherbaby attachment than control group ( $p$ value<0.05). Discussion: This study showed that Maternal Role Attainment Health Education effectives improving maternal role attainment in early married women. It is suggested involving a randomized control trial design for further research.
\end{abstract}

Keywords: maternal role attainment health education, maternal role satisfaction, early married 


\section{PENDAHULUAN}

Pernikahan dini merupakan sebuah ikatan pernikahan resmi atau pun informal sebelum anak laki-laki dan perempuan berusia 18 tahun (United Nations Emergency Children's Fund/UNICEF, 2014). Fenomena pernikahan dini masih banyak terjadi di Indonesia. Menurut laporan Riset Kesehatan Dasar (Riskesdas) tahun 2013, terdapat $2,6 \%$ wanita di Indonesia yang usia pernikahan pertamanya kurang dari 15 tahun dan sebanyak $23,9 \%$ menikah pada usia 1519 tahun (Badan Penelitian dan Pengembangan Kesehatan Kementerian Kesehatan Republik Indonesia, 2013).

Pemerintah melalui Badan Koordinasi Keluarga Berencana Nasional (BKKBN) berupaya mengurangi fenomena tersebut dengan menyelenggarakan program pendewasaan usia perkawinan. Program tersebut diharapkan dapat meningkatkan usia perkawinan pertama sesuai anjuran pemerintah, yaitu 20 tahun bagi perempuan dan 25 tahun bagi laki-laki (Sriudiyani \& Soebijanto, 2011).

Mercer (1986) cit Alligood \& Tomey (2014) menyebutkan bahwa identitas peran ibu merupakan pandangan seorang wanita yang telah terintegrasi di dalam dirinya sendiri menjadi seorang ibu yang sesungguhnya. Indikator tercapainya identitas peran ibu yaitu adanya kepercayaan diri, kepuasan menjalankan peran ibu, serta ikatan tali kasih ibu-bayi. Indikator identitas peran ibu penting untuk dicapai secara optimal karena pada akhirnya dapat mempengaruhi outcome pada anak. Indikator tersebut dipengaruhi oleh beberapa faktor, di antaranya adalah usia ibu. Ibu yang masih berusia remaja memiliki risiko pencapaian identitas peran ibu yang lebih rendah.

Hendari (2012) melaporkan bahwa usia ibu $\leq 20$ tahun memiliki peningkatan faktor risiko terhadap kemungkinan kematian bayinya. Hal ini disebabkan oleh organ reproduksi ibu yang belum sempurna untuk menerima kehamilan dan melahirkan serta kurangnya kemampuan ibu muda dalam merawat bayi.
Febriastuti, et al (2013) juga meneliti hubungan usia ibu dengan kemampuan merawat bayi. Ditemukan bahwa usia ibu yang terlalu muda disertai dengan tingkat pendidikan yang rendah menyebabkan ibu kurang mampu merawat bayinya.

Tercapainya indikator identitas peran ibu, baik kepercayaan diri dan kepuasan menjalankan peran ibu, maupun ikatan tali kasih ibu-bayi, dapat difasilitasi melalui pemberian pendidikan kesehatan (Santy, 2011; Özkan \& Polat, 2011; Kusumaningsih, 2012; Saleh, et al, 2014). Penelitian mengenai pengaruh Pendidikan Kesehatan Identitas Peran Ibu terhadap indikator tercapainya identitas peran ibu pada wanita yang melakukan pernikahan dini di Provinsi Daerah Istimewa Yogyakarta (DIY) belum pernah dilakukan. Berdasarkan hasil wawancara via telepon dengan pengelola Pusat Keluarga Berencana Indonesia (PKBI) di Sleman, diketahui bahwa pendidikan kesehatan yang selama ini diberikan kepada subyek remaja pada umumnya bertujuan untuk mencegah pernikahan dini dan meningkatkan pengetahuan tentang kesehatan reproduksi remaja. Belum ada intervensi pendidikan kesehatan bagi remaja yang telah menikah dini dan memiliki bayi. Padahal, mereka juga membutuhkan pendidikan dan bimbingan untuk membantu mereka mencapai identitas ibu secara optimal.

Pendidikan kesehatan ini perlu diberikan karena angka pernikahan dini di Provinsi DIY masih cukup tinggi. Terdapat $22,37 \%$ wanita yang menikah pada usia 16-18 tahun dan $3,7 \%$ wanita menikah pada usia $\leq 15$ tahun di Provinsi DIY pada tahun 2012 (Direktorat Perencanaan Pengendalian Penduduk BKKBN, 2012). Pada tahun tersebut, Kabupaten Bantul menjadi daerah yang mengajukan dispensasi menikah tertinggi kedua setelah Kabupaten Gunung Kidul. Terdapat 151 calon pengantin yang mengajukan dispensasi menikah di bawah umur (Pemerintah Kabupaten Bantul, 2013). Berdasarkan hasil penelitian Khilmiyah (2014) diketahui bahwa Kecamatan 
Banguntapan merupakan daerah dengan angka pernikahan dini tertinggi kedua di Kabupaten Bantul. Oleh karena itu, dilakukan penelitian tentang pengaruh pendidikan kesehatan pada wanita yang melakukan pernikahan dini di Kecamatan Banguntapan, Bantul, Yogyakarta. Diharapkan agar penelitian ini dapat memfasilitasi tercapainya indikator identitas peran ibu secara optimal, baik kepercayaan diri dan kepuasan peran ibu, maupun ikatan tali kasih ibu-bayi. Selain itu, penelitian ini harapkan menggugah tenaga kesehatan, khususnya perawat, agar memberikan pendidikan kesehatan yang berkelanjutan bagi wanita yang melakukan pernikahan dini.

\section{BAHAN DAN METODE}

Penelitian ini merupakan penelitian quasiexperiment dengan pendekatan pretest and posttest design. Subyek penelitian ini adalah 60 wanita yang telah menikah pada usia $\leq 18$ tahun, pada saat penelitian berusia $\leq 24$ tahun, dan hanya memiliki bayi usia 0-12 bulan di wilayah kerja Puskesmas Kecamatan Banguntapan, Bantul, Yogyakarta pada Juli-Agustus 2015.

Subyek penelitian direkrut dengan teknik consecutive sampling. Subyek penelitian dibagi dua, yaitu kelompok Penkes PIPI $(n=30)$ yang diberikan pendidikan kesehatan perseorangan dengan media booklet, demonstrasi dan latihan perawatan bayi, serta konseling via telepon pada 1 minggu pascaintervensi. Kelompok ceramah $(n=30)$ yang hanya diberikan edukasi individu. Kedua kelompok diberikan pretest (sebelum perlakuan), posttest 1 (segera sesudah perlakuan), dan posttest 2 (10-14 hari setelah perlakuan). Instrumen yang digunakan yaitu kuesioner kepercayaan diri dan kepuasan peran ibu, serta kuesioner ikatan kasih sayang ibu dan bayi. Uji statistik yang digunakan yaitu Paired $t$ Test, Independent t Test, dan Regresi Linier Berganda.

HASIL
Sebanyak 63 responden masuk dalam kriteria inklusi penelitian ini, 32 responden dalam kelompok Penkes PIPI dan 31 responden dalam kelompok ceramah. Namun, pada saat penelitian berlangsung terdapat 3 responden yang loss of follow up, 1 responden dari kelompok Penkes PIPI dan 2 responden dari kelompok ceramah. Sebanyak masing-masing 30 responden pada kelompok Penkes PIPI dan ceramah akhirnya diikutkan dalam analisis penelitian ini.

Hasil analisis univariat menunjukkan bahwa rata-rata responden berusia 18,5 tahun pada kelompok Penkes PIPI dan 19 tahun pada kelompok ceramah. Usia menikah pertama kali rata-rata 17,07 tahun pada kelompok Penkes PIPI dan 17,40 tahun pada kelompok ceramah. Seluruh responden berstatus menikah, primipara, dan tidak memiliki riwayat bayi meninggal. Sebanyak $76,7 \%$ responden kelompok Penkes PIPI berpendidikan SMP-SMA. Begitu juga responden kelompok ceramah, sebanyak $86,7 \%$ berpendidikan SMP-SMA. Kedua kelompok sama-sama melahirkan secara spontan sebanyak 83,3\%, merasakan dukungan suami sebanyak $73,3 \%$, dan memiliki bayi yang pernah dirawat inap di fasilitas kesehatan sebanyak 26,7\%. Usia bayi responden rata-rata 6,9 bulan pada kelompok Penkes PIPI dan 7,4 bulan pada kelompok ceramah.

Hasil rerata skor pretest kepercayaan diri dan kepuasan peran ibu serta ikatan tali kasih ibu-bayi pada kelompok Penkes PIPI sebesar 53,77 ( $p$ value $=0,063)$ dan kelompok ceramah sebesar 51,23 ( $p$ value $=$ 0,052 ). Kedua kelompok memiliki $p$ value $>0,05$, artinya tidak ada perbedaan rerata skor pretest yang bermakna antara kelompok Penkes PIPI dan kelompok ceramah. Begitu juga hasil uji homogenitas kedua variabel tersebut sama-sama tidak bermakna $(p=0,527$ dan $p=0,081 ; p>0,005)$. Hal tersebut menunjukkan bahwa tidak ada perbedaan kepercayaan diri dan kepuasan peran ibu serta ikatan tali kasih ibu-bayi pada kedua kelompok sebelum diberikan 
pendidikan kesehatan. Dengan kata lain, kedua kelompok adalah homogen atau setara pada saat pretest.

Tabel 1 menunjukkan bahwa hasil uji setiap variabel pada kelompok Penkes PIPI memiliki nilai p <0,05. Maka, dapat disimpulkan bahwa terdapat perbedaan bermakna skor rerata kepercayaan diri dan kepuasan peran ibu antara sebelum dan sesudah mendapat perlakuan. Hal tersebut juga berarti bahwa pendidikan kesehatan dapat mempengaruhi kepercayaan diri dan kepuasan peran ibu pada wanita yang melakukan pernikahan dini. Pada kelompok ceramah semua variabel memiliki nilai $p<0,05$, kecuali skor ikatan tali kasih ibu-bayi pada bagian posttest 1 dan 2 .

Tabel 2 menunjukkan bahwa terdapat perbedaan peningkatan rerata skor antara kelompok Penkes PIPI dan ceramah pada posttest 2 dengan nilai $p<0,05$. Hal itu menunjukkan bahwa perlakuan pada kelompok Penkes PIPI lebih efektif meningkatkan kepercayaan diri dan kepuasan peran ibu serta ikatan tali kasih ibu-bayi dibandingkan kelompok ceramah.

Tabel 3 menunjukkan hasil uji korelasi Spearman untuk mengetahui hubungan antara tingkat pendidikan, pengalaman merawat bayi, riwayat persalinan, dan dukungan suami dengan skor posttest 2 kepercayaan diri dan kepuasan peran ibu serta ikatan tali kasih ibu-bayi. Uji ini menggunakan data posttest 2 karena data dianggap telah lengkap terkumpul setelah seluruh tahap prosedur pelaksanaan penelitian selesai dilakukan. Variabel yang memiliki nilai $p<0,25$ dimasukkan ke dalam regresi linier berganda. Hasil uji tersebut disajikan pada Tabel 4.

Tabel 4 menunjukkan bahwa pemberian pendidikan kesehatan bersama-sama dengan variabel riwayat persalinan mempengaruhi kepercayaan diri dan kepuasan menjalankan peran ibu sebesar $17,5 \% \quad(R 2=0,175)$. Pemberian pendidikan kesehatan dapat meningkatkan skor posttest 2 kepercayaan diri dan kepuasan peran ibu sebesar 4,5. Selain itu, Tabel 4 menunjukkan bahwa pemberian pendidikan kesehatan mempengaruhi ikatan tali kasih ibu-bayi sebesar 10,6\% dan mampu meningkatkan skor variabel tersebut sebesar 4,233.

\section{PEMBAHASAN}

Hasil Paired t Test menunjukkan bahwa terdapat peningkatan rerata skor yang bermakna dari pretest ke posttest 1 dan 2 pada kedua kelompok (Tabel 1). Hal ini berarti bahwa pendidikan kesehatan yang diberikan dapat meningkatkan kepercayaan diri dan kepuasan peran ibu.

Beberapa penelitian terdahulu sejalan dengan hasil penelitian ini. Çınar \& Öztürk (2014) melakukan penelitian tentang efektivitas planned baby care education yang ditujukan kepada ibu primipara terhadap ikatan tali kasih ibu dengan bayi dan tingkat kepercayaan diri mereka. Hasil penelitian tersebut menunjukkan bahwa responden yang mendapat intervensi tersebut dapat meningkatkan ikatan tali kasih ibu dengan bayi dan tingkat kepercayaan diri ibu dibandingkan dengan dengan responden yang tidak menerima intervensi tersebut.

Tabel 1. Hasil Paired t Test Kepercayaan Diri dan Kepuasan Peran Ibu serta Ikatan Tali Kasih Ibu-Bayi pada Kelompok Penkes PIPI dan Ceramah

\begin{tabular}{|c|c|c|c|c|c|c|}
\hline \multirow[t]{2}{*}{ Waktu } & \multicolumn{3}{|c|}{ Kelompok Penkes PIPI } & \multicolumn{3}{|c|}{ Kelompok Ceramah } \\
\hline & Mean(SD) & $\mathrm{p}$ & $\mathrm{Cl} 95 \%$ & Mean(SD) & $\mathrm{p}$ & $\mathrm{Cl} 95 \%$ \\
\hline \multicolumn{7}{|c|}{ Kepercayaan Diri dan Kepuasan Peran Ibu } \\
\hline $\begin{array}{l}\text { Pretest- } \\
\text { Posttest } 1\end{array}$ & $\begin{array}{l}53,77(4,812 \\
58,53(4,191\end{array}$ & 0,00 & $3,501-6,033$ & $\begin{array}{l}51,23(5,532) \\
54,70(5,772)\end{array}$ & 0,001 & $2,430-4,503$ \\
\hline
\end{tabular}




\begin{tabular}{|c|c|c|c|c|c|c|}
\hline $\begin{array}{l}\text { Pretest- } \\
\text { Posttest } 2\end{array}$ & $\begin{array}{l}53,77(4,812) \\
62,03(4,986)\end{array}$ & 0,001 & $6,419-10,114$ & $\begin{array}{l}51,23(5,532) \\
57,53(5,818)\end{array}$ & 0,001 & $4,822-7,778$ \\
\hline $\begin{array}{l}\text { Posttest 1- } \\
\text { Posttest } 2\end{array}$ & $\begin{array}{l}58,53(4,191) \\
62,03(4,986)\end{array}$ & 0,001 & $2,387-4,613$ & $\begin{array}{l}54,70(5,772) \\
57,53(5,818)\end{array}$ & 0,01 & $1,823-3,843$ \\
\hline \multicolumn{7}{|c|}{ Ikatan Tali Kasih Ibu-Bayi } \\
\hline $\begin{array}{l}\text { Pretest - } \\
\text { Posttest } 1\end{array}$ & $\begin{array}{l}48,07(3,965) \\
55,47(3,288)\end{array}$ & 0,001 & $6,086-8,714$ & $\begin{array}{l}50,40(5,083) \\
52,03(5,436)\end{array}$ & 0,001 & $0,896-2,370$ \\
\hline $\begin{array}{l}\text { Pretest- } \\
\text { Posttest } 2\end{array}$ & $\begin{array}{l}48,07(3,965) \\
56,57(3,919)\end{array}$ & 0,001 & $7,272-9,728$ & $\begin{array}{l}50,40(5,083) \\
52,33(7,222)\end{array}$ & 0,01 & $0,496-3,371$ \\
\hline $\begin{array}{l}\text { Posttest 1- } \\
\text { Posttest } 2\end{array}$ & $\begin{array}{l}55,47(3,288) \\
56,57(3,919)\end{array}$ & 0,001 & $1,377-1,823$ & $\begin{array}{l}52,03(5,436) \\
52,33(7,222)\end{array}$ & 0,54 & $-0,710-1,310$ \\
\hline
\end{tabular}

Tabel 2. Hasil Akhir Independent t Test Perbedaan Kepercayaan Diri dan Kepuasan Peran Ibu serta Ikatan Tali Kasih Ibu-Bayi antara Kelompok Penkes PIPI dan Ceramah

\begin{tabular}{|c|c|c|c|c|c|c|c|}
\hline \multirow[t]{2}{*}{ Variabel } & \multirow[t]{2}{*}{ Waktu } & \multicolumn{2}{|c|}{$\begin{array}{c}\text { Kelompok } \\
\text { Penkes PIPI }\end{array}$} & \multicolumn{2}{|r|}{$\begin{array}{c}\text { Kelompok } \\
\text { Ceramah }\end{array}$} & \multirow[t]{2}{*}{$p$} & \multirow[t]{2}{*}{$\begin{array}{c}\mathrm{Cl} \\
95 \%\end{array}$} \\
\hline & & $\mathrm{n}$ & Mean (SD) & $\mathrm{n}$ & Mean (SD) & & \\
\hline $\begin{array}{l}\text { Kepercayaan Diri } \\
\text { dan Kepuasan } \\
\text { Peran Ibu }\end{array}$ & $\begin{array}{l}\text { Post- } \\
\text { test } 2\end{array}$ & 30 & $62,03(4,986)$ & 30 & $57,53(5,818)$ & 0,002 & $1,700-7,300$ \\
\hline $\begin{array}{l}\text { Ikatan Tali Kasih } \\
\text { Ibu-Bayi }\end{array}$ & $\begin{array}{l}\text { Post- } \\
\text { test } 2\end{array}$ & 30 & $56,57(3,919)$ & 30 & $52,33(7,222)$ & 0,007 & $1,230-7,236$ \\
\hline
\end{tabular}

Tabel 3. Hasil Uji Korelasi Spearman

\begin{tabular}{lcc}
\hline \multicolumn{1}{c}{ Hubungan Variabel } & \multicolumn{2}{c}{ Posttest 2 } \\
& $\mathrm{R}$ & p-value \\
\hline Kepercayaan Diri dan Kepuasan Peran & & \\
lbu dengan: & & \\
Pemberian Pendidikan Kesehatan & 0,363 & 0,004 \\
Tingkat Pendidikan & 0,171 & 0,291 \\
Pengalaman Merawat Bayi & 0,077 & 0,560 \\
Riwayat Persalinan & 0,200 & 0,126 \\
Dukungan Suami & 0,165 & 0,268 \\
\hline Ikatan Tali Kasih Ibu-Bayi dengan: & & \\
Pemberian Pendidikan Kesehatan & 0,285 & 0,027 \\
Tingkat Pendidikan & 0,181 & 0,267 \\
Pengalaman Merawat Bayi & 0,024 & 0,858 \\
Riwayat Persalinan & 0,067 & 0,613 \\
Dukungan Suami & 0,156 & 0,254 \\
\hline
\end{tabular}

Tabel 4. Hasil Pemodelan Akhir Analisis Multivariat

\begin{tabular}{|c|c|c|c|c|c|c|}
\hline $\begin{array}{c}\text { Variabel } \\
\text { Bebas }\end{array}$ & $\begin{array}{l}\text { Variabel } \\
\text { Luar }\end{array}$ & B & Beta & $\begin{array}{c}p- \\
\text { value }\end{array}$ & $\begin{array}{c}\mathrm{Cl} \\
95 \%\end{array}$ & $\mathrm{R}^{2}$ \\
\hline Kepercayaan & Pemberian & 4,500 & 0,389 & 0,002 & $1,761-$ & \multirow{4}{*}{0,175} \\
\hline Diri & Pendidikan & & & & 7,239 & \\
\hline Kepuasan & Kesehatan & & & & & \\
\hline Peran lbu & $\begin{array}{l}\text { Riwayat } \\
\text { Persalinan }\end{array}$ & 2,750 & 0,226 & 0,061 & $\begin{array}{c}0,126- \\
5,626 \\
\end{array}$ & \\
\hline $\begin{array}{ll}\text { Ikatan } & \text { Tali } \\
\text { Kasih } & \text { Ibu- } \\
\text { Bavi } & \end{array}$ & $\begin{array}{l}\text { Pemberian } \\
\text { Pendidikan } \\
\text { Kesehatan }\end{array}$ & 4,233 & 0,347 & 0,007 & $\begin{array}{l}1,230- \\
7,236\end{array}$ & 0,106 \\
\hline
\end{tabular}


Dari hasil penelitian tersebut disimpulkan bahwa edukasi dapat menjadi alat yang efektif untuk meningkatkan maternal attachment dan kepercayaan diri ibu.

Hasil penelitian Özkan \& Polat (2011) menyebutkan bahwa intervensi berupa Maternal Identity Development Education (MIDA) yang diberikan kepada ibu primipara dapat meningkatkan skor persepsi yang positif terhadap bayi mereka. Hal ini mendukung hubungan yang positif antara ibu dan bayi. Mereka berpendapat bahwa edukasi yang diberikan kepada ibu tentang perawatan diri dan bayi efektif dalam mengurangi kecemasan mereka serta meningkatkan rasa kompetensi, kepercayaan diri, ikatan kasih sayang dengan bayi serta pencapaian identitas maternal.

Hasil posttest 2 kepercayaan diri dan kepuasan menjalankan peran ibu pada kelompok ceramah juga terdapat peningkatan skor yang bermakna meskipun tidak diberikan intervensi apapun di antara selang waktu posttest 1 ke posttest 2 . Hal ini mungkin disebabkan oleh faktor responden yang tinggal bersama dengan bayi dan berinteraksi dengannya. Hal tersebut secara tidak langsung dapat melatih kemampuan responden merawat bayi dan meningkatkan kepercayaan diri mereka. Menurut Mercer (2004), dibutuhkan cukup banyak waktu untuk mempelajari peran ibu bagi mereka yang baru pertama kali menjadi seorang ibu. Melalui interaksi sehari-hari dengan bayi di dalam komponen mikrosistem, ibu melatih praktik perawatan bayi dengan trial and error serta mempelajari respon bayi terhadap dirinya dan orang lain. Dengan begitu, ibu memahami cara merawat bayi dengan baik dan mampu membuat bayi merasa nyaman. Hal tersebut menunjukkan bahwa kebersamaan ibu dan bayi melalui praktik perawatan bayi sehari-hari mampu memfasilitasi kepercayaan diri dan rasa kompetensi mereka sebagai seorang ibu.
Hasil posttest 2 ikatan tali kasih ibu dan bayi pada kelompok ceramah menunjukkan tidak terdapat peningkatan skor yang bermakna karena memang tidak diberikan intervensi apapun di antara selang waktu posttest $1 \mathrm{ke}$ posttest 2. Meskipun selama selang waktu antara posttest 1 dan 2 responden tetap merawat bayinya, ternyata hal tersebut tidak secara langsung dapat meningkatkan ikatan tali kasih di antara mereka. Mereka dapat menjadi fasih dalam praktik perawatan bayi sehari-hari karena memang telah menjadi rutinitas mereka. Tetapi, belum tentu hal tersebut dilakukan dengan diliputi perasaan kasih sayang terhadap bayi.

Aktivitas perawatan bayi yang dilakukan sehari-hari oleh ibu tidak secara otomatis dapat meningkatkan hubungan kasih sayang antara ibu dan bayi. Apabila ibu terlalu fokus terhadap pekerjaan merawat bayi, ibu menjadi kurang sensitif ketika berinteraksi dengan bayi. lbu yang lebih banyak berfokus terhadap pekerjaan merawat bayi, mengajar anak, menjauhkan mainan yang berbahaya bagi bayi, atau melarang bayi menyentuh benda yang diinginkan, umumnya kurang sensitif untuk mengembangkan aspek sosioemosi saat berinteraksi dengan bayi. Apabila ibu terlibat aktif dalam memainkan mainan bersama bayi, atau menikmati waktu memberikan makanan ringan untuk bayi, ibu memiliki sensitivitas maternal yang lebih tinggi sehingga mendukung ikatan kasih sayang dengan bayi (Pridham, 2010). Dengan demikian, kebersamaan ibu dan bayi dalam interaksi perawatan bayi seharihari berpeluang meningkatkan kepercayaan diri dan kepuasan menjalankan peran ibu, namun tidak selalu otomatis meningkatkan hubungan kasih sayang di antara mereka.

Peningkatan rerata skor posttest 2 kepercayaan diri dan kepuasan menjalankan peran ibu pada kelompok Penkes PIPI lebih tinggi daripada kelompok ceramah. Hal ini mungkin terjadi karena kelompok Penkes PIPI diberikan pendidikan kesehatan perseorangan dengan metode yang lebih 
beragam yaitu ditambah dengan demonstrasi, latihan, serta konseling via telepon pada 1 minggu pascaintervensi.

Ragam metode yang digunakan dalam penelitian ini dapat merangsang responden untuk menerima informasi dengan menggunakan pancaindra yang lebih banyak. Elgar Dale (1969) menyebutkan bahwa penggunaan media yang lebih banyak dalam proses pembelajaran dapat memfasilitasi pemahaman yang lebih tinggi karena lebih banyak indra yang digunakan untuk menyerap informasi. Berdasarkan teori kerucut Elgar Dale, maka penelitian ini menggunakan 4 media/alat peraga dengan tingkat intensitas 1, yaitu, kata-kata yang berupa penyampaian pendidikan kesehatan perseorangan; tingkat intensitas 2, yaitu tulisan, yang berupa booklet; tingkat intensitas 8, yaitu demonstrasi perawatan bayi; dan tingkat intensitas 10 , yaitu benda tiruan, berupa phantom bayi, peralatan untuk mandi, makan, dan menstimulasi bayi (Maulana, 2009).

Hasil pemodelan akhir analisis multivariat (Tabel 4) menunjukkan bahwa pemberian pendidikan kesehatan dapat meningkatkan skor posttest 2 kepercayaan diri dan kepuasan peran ibu setelah dikontrol oleh riwayat persalinan. Di sisi lain, skor posttest 2 ikatan tali kasih ibu-bayi tidak dipengaruhi oleh variabel luar. Hal itu berarti bahwa peningkatan mean skor ikatan tali kasih ibubayi terjadi karena peran dari pemberian pendidikan kesehatan.

Riwayat pengalaman melahirkan mempengaruhi pencapaian identitas peran ibu karena persalinan dianggap sebagai pintu masuk resmi menjadi seorang ibu (Mercer, 2004). Pernyataan tersebut sesuai dengan hasil penelitian ini bahwa riwayat persalinan merupakan variabel yang berpengaruh terhadap kepercayaan diri dan kepuasan peran ibu sebagai salah satu indikator dari tercapainya identitas peran ibu. Meskipun begitu, riwayat persalinan di dalam penelitian ini tidak mempunyai pengaruh signifikan terhadap ikatan tali kasih ibu-bayi.
Hal ini mungkin disebabkan karena responden pada saat penelitian lebih fokus terhadap pengembangan hubungannya dengan bayi dan segala perawatan yang dibutuhkan bayi dibandingkan dengan pengalaman melahirkan terdahulu. Meskipun begitu, hasil penelitian Budris (1988) sejalan dengan analisis penelitian ini. Dilaporkan bahwa tidak ada pengaruh yang signifikan antara metode persalinan terhadap identitas peran ibu. Hasil

penelitian ini menunjukkan bahwa tingkat pendidikan tidak berpengaruh terhadap pencapaian identitas peran ibu. Hal ini tidak sejalan dengan hasil penelitian Goto, et al (2007) yang melaporkan bahwa tingkat pendidikan berpengaruh terhadap pencapaian identitas peran ibu. Lebih jauh diterangkan bahwa ibu dengan tingkat pendidikan yang lebih tinggi, misalnya level perguruan tinggi, lebih mampu mengungkapkan kesulitannya dalam merawat dan lebih cepat belajar tentang perawatan bayi. Hal tersebut tidak sesuai dengan hasil analisis multivariat pada penelitian ini. Hal ini mungkin dapat terjadi karena hasil uji statistik tingkat pendidikan responden pada penelitian ini adalah homogen. Sejak awal penelitian ini, homogenitas memang diharapkan agar tingkat pendidikan responden tidak mempengaruhi pencapaian identitas peran ibu. Dengan demikian, dapat terlihat efektivitas pendidikan kesehatan yang diberikan setelah upaya mengurangi bias yang mungkin terjadi.

Hasil analisis multivariat dalam penelitian ini juga menunjukkan bahwa pengalaman merawat bayi sebelumnya tidak memiliki pengaruh yang signifikan terhadap kepercayaan diri dan kepuasan menjalankan peran ibu maupun ikatan tali kasih ibu dan bayi. Hal ini dapat disebabkan oleh faktor responden dalam penelitian ini yang masih berusia muda. Faktor usia merupakan salah satu variabel yang berpengaruh terhadap pencapaian identitas peran ibu (Mercer, 1986 di dalam Alligood, 2010; Oktafiani, et al, 2014). Ketidaksiapan mental responden yang masih berusia dini untuk memiliki bayi 
berpengaruh terhadap hasil analisis. Meskipun mereka pernah merawat bayi sebelumnya, baik dari keluarga atau tetangga, namun bayi tersebut tidak menjadi tanggung jawab mereka sepenuhnya karena mereka bukan ibu kandung bayi tersebut. Dapat menjadi beban tersendiri yang menyangkut kepada kepercayaan diri menjadi seorang ibu dan ikatan kasih sayang dengan bayi ketika mereka harus mengasuh bayi sendiri di usia dini. Hal tersebut sejalan dengan hasil penelitian Ngantung, et al (2012) yang menyebutkan bahwa pada responden mahasiswi yang berusia remaja akhir memiliki beberapa kendala dalam penyesuaian perkawinan. Salah satunya adalah penyesuaian peran sebagai seorang ibu dan istri.

Penelitian yang dilakukan Russel (2006) sejalan dengan hasil penelitian ini. Hasil penelitiannya yang berjudul Maternal Confidence of First-time Mothers during Their Child's Infancy menemukan beberapa faktor maternal yang tidak berhubungan dengan kepercayaan diri menjadi seorang ibu. Penelitian ini difokuskan kepada responden yang baru pertama kali menjadi seorang ibu. Ditemukan bahwa tingkat pendidikan ibu dan pengalaman merawat bayi sebelumnya tidak berhubungan dengan kepercayaan diri menjadi seorang ibu pada periode pertama mereka menjadi seorang ibu.

Hasil penelitian ini juga menemukan bahwa variabel dukungan suami tidak memiliki pengaruh yang signifikan terhadap pencapaian identitas peran ibu. Hal ini tidak sejalan dengan pendapat Mercer (1986) di dalam Alligood \& Tomey (2014) yang menyebutkan bahwa peran pasangan (suami) dapat mencerminkan kompetensi ibu dalam menjalankan perannya sebagai ibu melalui pertumbuhan dan perkembangan.

Penelitian yang dilakukan oleh Sampson pada tahun 2009 menemukan bahwa dukungan dari pasangan yang dirasakan oleh responden dapat menurunkan tingkat stres maternal. Dukungan yang dimaksud dapat berupa dukungan emosional, pengasuhan bayi, dan perlengkapan yang dibutuhkan. Dukungan dari pasangan menjadi sangat penting selama tahun pertama menjadi seorang ibu. Tetapi, hasil penelitian tersebut menyatakan bahwa tidak semua jenis dukungan yang dirasakan oleh ibu dapat menurunkan tingkat stres ibu dengan pengaruh yang sama besar.

Penelitian ini menyimpulkan bahwa dukungan suami tidak berhubungan dengan pencapaian identitas peran ibu. Hal ini mungkin terjadi karena responden juga memiliki sumber dukungan sosial selain dari suami. Data karakteristik responden pada penelitian ini menunjukkan bahwa mayoritas responden merasakan dukungan dari orangtua atau keluarga besar. Selain itu, mayoritas responden termasuk ke dalam extended family sehingga memungkinkan bagi mereka mendapat dukungan yang lebih banyak. Pada saat bersalin, responden juga ditunggui tidak hanya oleh suami, tetapi juga oleh keluarga besar.

Taylor (1995) menyebutkan bahwa seseorang yang mendapat dukungan sosial keluarga yang tinggi dapat menurunkan tingkat stres dan meningkatkan keberhasilan beradapatasi dengan situasi. Lesly (2012) juga mendukung pernyataan tersebut melalui penelitian kualitatif yang berjudul Adaptation to the Motherhood Role: Experiences and Perceptions of First-time Mothers: A Pilot Study. Dilaporkan bahwa transisi seorang wanita ketika menjadi ibu untuk pertama kalinya difasilitasi oleh tiga hal yaitu, dukungan keluarga, persiapan menjadi ibu, dan intervensi edukasi. Oleh karena itu, Lesly (2012) merekomendasikan agar diadakan program interdispliner dalam upaya mengedukasi dan memfasilitasi adaptasi serta transisi peran menjadi seorang ibu.

Mayoritas responden mendapat dukungan dari orangtua dan keluarga besar serta tinggal bersama mereka dan mendapat pendidikan kesehatan yang meningkatkan 
kepercayaan diri dan kepuasan peran ibu serta ikatan tali kasih ibu-bayi. Hal ini dapat berpengaruh terhadap analisis multivariat dalam penelitian ini. Dalam penelitian ini, dukungan suami belum cukup berpengaruh terhadap identitas ibu tanpa disertai dukungan dari keluarga besar atau sumber dukungan sosial lainnya.

\section{KESIMPULAN}

Pendidikan Kesehatan Pencapaian Identitas Peran lbu dapat meningkatkan pencapaian indikator identitas peran ibu, baik kepercayaan diri dan kepuasan peran ibu, maupun ikatan tali kasih ibu-bayi pada wanita yang melakukan pernikahan dini.

Penelitian ini membuktikan bahwa pendidikan kesehatan perseorangan dan konseling berkelanjutan dapat meningkatkan pencapaian identitas peran ibu pada wanita yang menikah dini. Oleh karena itu, direkomendasikan agar perawat memberikan pendidikan kesehatan berkelanjutan bagai wanita yang melakukan pernikahan dini agar dapat meningkatkan pencapaian identitas peran mereka sebagai ibu. Direkomendasikan juga kepada pemerintah agar tidak hanya berfokus pada pemberian edukasi untuk mencegah pernikahan dini pada remaja, tetapi juga memberikan edukasi bagi remaja yang sudah terlanjur menikah dini dan memiliki bayi. Mereka perlu mendapat bimbingan dan informasi yang sesuai agar dapat mencapai identitas perannya sebagai ibu.

Peneliti merekomendasikan bagi peneliti selanjutnya agar menggunakan level desain penelitian yang lebih tinggi seperti randomized control trial untuk penelitian serupa. Hal ini bertujuan agar didapat hasil penelitian yang lebih akurat dan kaya informasi. Dengan begitu, tingkat pencapaian identitas peran ibu pada wanita menikah dini dapat dicapai dengan lebih optimal.

\section{DAFTAR PUSTAKA}

Alligood, M.R., \& Tomey, A.M. (2014). Nursing Theorist and Their Work. Missouri: Mosby Elsevier.

Badan Penelitian dan Pengembangan Kesehatan Kementerian Kesehatan Republik Indonesia (Balitbangkes $\mathrm{RI})$. (2013). Riset Kesehatan Dasar (Riskesdas) 2013. Diakses dari http://www.depkes.go.id/resources/d ownload/general/Hasil\%20Riskesda s\%202013.pdf

Budris, E. F. (1988). The Effect of Infant Behavior Education on Maternal Role Attainment. ProQuest Dissertations Publishing, Master of Science Southern Connecticut State University. UMI: 1333178. Diakses dari

http://search.proquest.com/docview/ 303800012/fulltextPDF/B6028200C8 A40BBPQ/1 ?accountid $=13771$.

Çınar, I. O \& Öztürk, A. (2014). The Effect of Planned Baby Care Education Gucen to Primioarous Mothers $n$ Maternal Attachment and Self-Confidence Levels. Health Care for Women International, 35: 320-333. ISSN: 739-9332 print / 1096-4665 online. DOI:

10.1080/07399332.2013.842240.

Diakses dari http://www.researchgate.net/profile/ll guen_Cinar/publication/258632294_ The_Effect_of_Planned_Baby_Care Education_Given_to_Primiparous_ Mothers_on_Maternal_Attachment_ and_Self-

Confidence_Levels/links/550941fe0c f2d7a2812c5244.pdf? inViewer=true \&disableCoverPage =true\&origin $=p u$ blication_detail

Direktorat Perencanaan Pengendalian Penduduk Badan Kependudukan dan Keluarga Berencana Nasional. (2012). Factsheet: Tren Fertilitas dan Keluarga Berencana Berdasarkan Data Survei Sosial Ekonomi Nasional (Susenas) Tahun 2006-2012 di Provinsi D.I. Yogyakarta. Diakses dari

http://www.bkkbn.go.id/kependuduka 
n/DITRENDUK/Factsheet\%20Fertilt as\%20dan\%20Keluarga\%20Berenc ana/Factsheet\%20DI\%20Yogya.pdf Febriastuti, N., Arif, Y. S., \& Kusumaningring, T. (2013). Kepatuhan Orang Tua dalam Pemberian Kelengkapan Imunisasi Dasar pada Bayi 4-11 Bulan. Pediomaternal Nursing Journal Volume 2 Nomor 2. Diakses dari journal.unair.ac.id/filerPDF/pmnj323 cc1c63efull.docx

Goto, A. (2007). Maternal Confidence in Child Rearing: Comparing Data from Short-Term Prospective Survey among Japanese and Vietnam Mothers. Matern Child Health Journal, 12, pp. 613-618. Diakses dari

http://link.springer.com/article/10.100 7/s10995-007-0267-3/fulltext.html

Hendari, R., Widarsa, T. \& Wirawan, D.N. (2012). Faktor Determinan Kematian Bayi di Kabupaten Bima Tahun 2012. Tesis Magister IImu Kesehatan Masyarakat Universitas Udayana. Diakses dari http://ojs.unud.ac.id/index.php/phpm a/article/download/7876/5963.

Kusumaningsih, F. S. (2012). Pengaruh Pendidikan Kesehatan Perawatan Metode Kanguru Terhadap Keterampilan dan Kepercayaan Diri lbu untuk Memberikan ASI pada Bayi Berat Lahir Rendah. Tesis Fakultas IImu Keperawatan Universitas Indonesia. Diakses dari http://lib.ui.ac.id/file?file=digital/2031 7266-T31939-

Pengaruh\%20pendidikan.pdf.

Khilmiyah, A., Latief, H., Orbayinah, S., Aryekti, K., \& Sugiharti, S. (2014). Laporan Penelitian: Pandangan Remaja dan Orang Tua Terhadap Perniahan Dini dalam Membangun Keluarga di Kabupaten Bantul. Diakses dari yogya.bkkbn.go.id/data/.../BKKBN\% 20DIY\%20-\%20UMY.pdf.
Kusumaningsih, F. S. (2012). Pengaruh Pendidikan Kesehatan Perawatan Metode Kanguru Terhadap Keterampilan dan Kepercayaan Diri Ibu untuk Memberikan ASI pada Bayi Berat Lahir Rendah. Tesis Fakultas IImu Keperawatan Universitas Indonesia. Diakses dari http://lib.ui.ac.id/file?file=digital/2031 7266-T31939-

Pengaruh\%20pendidikan.pdf

Lesly, J. B. (2012). Adaptation to the Motherhood Role: Experiences and Perceptions of First-time Mothers, a Pilot Study. ProQuest Dissertation Publishing, unversity of Central Arkansas, UMI: 1516606. Diakses dari

http://search.proquest.com/docview/ 1037795731/5D31CEF72E04F01PQ $/ 1$ ?accountid=13771.

Maulana, H. D. J. (2009). Promosi Kesehatan. Jakarta: Penerbit Buku Kedokteran EGC.

Mercer, R. T. (2004). Becoming a Mother Versus Maternal Role Attainment. Journal of Scolarship: 3 (36); hal. 226-232.

Moser, M. H. (1989). The Effect of Infant Temperament, Maternal Stress, and Maternal Employment on Maternal Attachment to the Infant and Infant Attachment to the Mother. ProQuest Dissertations Publishing, George Manson University, 8919008. Diakses dari http://search.proquest.com/docview/ 303808075/7F0E36DD824448F1PQ $/ 1$ ?accountid=13771.

Ngantung, G. N. (2012). Penyesuaian Perkawinan pada Mahasiswi yang Menikah karena Hamil di Luar Nikah. Tugas kahir Fakultas Psikologi Universitas Kristen Satya Wacana. Diakses dari http://repository.uksw.edu/bitstream/ 123456789/2876/2/T1_802008109_ Full\%20text.pdf.

Oktafiani, S., Fajarsari, D., \& Mulidah, S. (2014). Pengaruh Usia dan Konsep Diri terhadap Pencapaian Peran Ibu 
Saat Bayi Berusia 0-6 Bulan di Desa Bojongsari, Kecamatan Bojongsari, Kabupaten Purbalingga. Bidan Prada: Jurnal IImiah Kebidanan, Vol. 5, No.1, Edisi Juni 2014, hlm: 33-42.

Özkan, H \& Polat, S. (2011). Maternal Identity Development Education on Maternity Role Attainment and My Baby Perception of Primiparas. Asian Nursing Research, Vol. 5, No. 2, pp.: 108-117.

Pemerintah Kabupaten Bantul. (2013). Fenomena Pernikahan Dini. Diakses dari http://www.bantulkab.go.id/berita/17 11.html.

Pridham, K. A., Lutz, K. F., Anderson, L. S., Riesch, S. K., \& Becker, P. T. (2010). Furthering the Understanding of parent-Child Relationships: A Nursing Scholarship Reviews Series. Part 3: Interaction and the ParentChild Relationship-Assesment and Intervenstion Studies. J Spec Pediatr Nur; 15(1): 33-61. Diakses dari http://www.ncbi.nlm.nih.gov/pmc/arti cles/PMC2835364/pdf/nihms176064 .pdf

Russell, K. (2006). Maternal Confidence of First-time Mothers during Their Child's Infancy. Dissertation, Georgia State University. Diakses dari http://scholarworks.gsu.edu/cgi/view content.cgi?article $=1000 \&$ context $=n$ ursing_diss.

Saleh, A., Nurochmah, E., As'ad, S., \& Hadju, V. (2014). Pengaruh Pendidikan Kesehatan dengan Pendekatan Modelling Terhadap Pengetahuan, Kemampuan Praktek dan Percaya Diri lbu dalam Menstimulasi Tumbuh Kembang Bayi 0-6 Bulan. Tesis Fakultas IImu Keperawatan Universitas Hasanudin. Diakses http://pasca.unhas.ac.id/jurnal/files/4 dfd694e7da095c426fa76ffbdf2b3ea. pdf.

Sampson, Maud McClain. (2009). Access to Resources and Maternal Well-being: Examining the Role of Educational Attainent in the Relationship Between Social Support and Maternal Parenting Stress at One Year Postpartum. ProQuest Dissertation Publishing, The Universityof Texas at Austin, UMI: 3684104. Diakses dari http://search.proquest.com/docview/ 1658783374/11A04987AF4749DEP $\mathrm{Q} / 1$ ?accountid=13771.

Santy, F. N. (2011). Pengalaman Remaja perempuan Single Parent Menjalani Peran Baru Sebagai Ibu di Wilayah Kerja Puskesmas Panjang Kota Bandar Lampung. Tesis Fakultas IImu Keperawatan Universitas Indonesia. Diakses dari http://lib.ui.ac.id/file?file=digital/2028 0900T\%20Fitri\%20Nuriya\%20Santy.pdf.

Sriudiyani, I. A. \& Soebijanto. (2011). Perkawinan Muda di Kalangan Perempuan: Mengapa? Policy Brief Pusat Penelitian dan Pengembangan Kependudukan-BKKBN, Seri I No.6/Pusdu-BKKBN?Desember 2011. Diakses dari http://www.bkkbn.go.id/litbang/pusdu /Hasil\%20Penelitian/Fertilitas/2011/ Perkawinan\%20Muda\%20Dikalanga n\%20Perempuan.pdf.

Taylor, S. E. (1995). Health Psychology. $3^{\text {rd }}$ edition. United States of America: Mc Graw-Hill.

United Nations Emergency Children's Fund (UNICEF). (2014). Child Protection from Violence, Exploitation, and Abuse. Diakses dari

http://www.unicef.org/protection/57929_580 08.html. 